\title{
Two new rare species of Candolleomyces with pale spores from China
}

\author{
Tolgor Bau', Jun-Qing Yan² \\ I Key Laboratory of Edible Fungal Resources and Utilization (North), Ministry of Agriculture and Rural Af- \\ fairs, Jilin Agricultural University, Changchun 130118, China 2 Jiangxi Key Laboratory for Conservation and \\ Utilization of Fungal Resource, Jiangxi Agricultural University, Nanchang, Jiangxi 330045, China
}

Corresponding authors: Tolgor Bau (junwusuo@126.com); Jun-Qing Yan (yanjunqing1990@126.com)

Academic editor: Bao-Kai Cui | Received 9 April 2021 | Accepted 23 May 2021 | Published 3 June 2021

Citation: Bau T, Yan J-Q (2021) Two new rare species of Candolleomyces with pale spores from China. MycoKeys 80: 149-161. https://doi.org/10.3897/mycokeys.80.67166

\begin{abstract}
Most species of Candolleomyces have brown or dark brown spores. Although pale-spored members are rare in the genus, we frequently collected two such species from many Provinces during our investigations in subtropical China from 2016-2020. As revealed by morphological characterisation and multigene phylogenetic analyses (ITS, LSU, $\beta$-tub and tef-1a), these species, which we have named C. subcacao and C. subminutisporus, are unique and distinct from known taxa. In addition, a new combination, $C$. cladiimarisci, is proposed on the basis of ITS sequence analysis of the type specimen. Detailed descriptions, colour photos, illustrations and a key to related species are presented.
\end{abstract}

\section{Keywords}

Basidiomycete, new taxon, Psathyrellaceae, phylogenetic analysis, taxonomy

\section{Introduction}

On the basis of extensive comparisons of gene sequences and phylogenetic analyses, the historical genus Psathyrella (Fr.) Quél. has been split into several genera. One of these genera is Candolleomyces D. Wächt. \& A. Melzer, which differs from Psathyrella s.s. in lacking pleurocystidia (Örstadius et al. 2015; Wächter and Melzer 2020). Approximately 100 taxa (including synonyms and subspecies) without pleurocystidia have been previously described in Psathyrella s.l. (Fries 1838; Smith 1972; Kits van Waveren 1985; Örstadius and Kundsen 2012; Battistin et al. 2014); however, many of these taxa

Copyright Tolgor Bau, Jun-Qing Yan. This is an open access article distributed under the terms of the Creative Commons Attribution License (CC BY 4.0), which permits unrestricted use, distribution, and reproduction in any medium, provided the original author and source are credited. 
have been treated as synonyms, as unique features, based on conventional methods, are scarce (Galland et al. 1979; Kits van Waveren 1980; Knudsen and Vesterholt 2012). Currently, 26 species have been assigned to Candolleomyces (Wächter \& Melzer, 2020).

According to the research of Wächter and Melzer (2020), Candolleomyces may be more speciose than previously thought and better delimitation of species boundaries is needed. Although controversies still exist regarding some species boundaries, the number of new taxa is steadily increasing (Melzer et al. 2018; Sicoli et al. 2019a; Büttner et al. 2020). This continuous discovery of new taxa with clear boundaries deepens understanding of the species in this genus.

Approximately eight taxa in the genus Candolleomyces have previously been reported from China (Yan 2018). During our investigations in subtropical China from 2016-2020, we frequently collected two unknown Candolleomyces species with pale spores from many Provinces. Spores that are pale or almost colourless in water and 5\% potassium hydroxide $(\mathrm{KOH})$ are very rare in this genus. On the basis of our morphological and phylogenetic analyses, the specimens are described as new species in this paper.

\section{Materials and methods}

\section{Morphological studies}

Specimens were deposited in the Herbarium of Mycology, Jilin Agricultural University (HMJAU) and the Herbarium of Fungi, Jiangxi Agricultural University (HFJAU). Macromorphological characters and habitat details were recorded from fresh basidiomata. Colour codes were based on the Methuen Handbook of Colour (Kornerup and Wanscher 1978). More than 30 spores, cystidia and basidia in water and 5\% aqueous $\mathrm{KOH}$ were measured under a microscope. In subsequent descriptions, measurements are shown as $(a) b-c(d)$, where $a$ is the lowest value, $b-c$ encompasses at least $90 \%$ of values and $d$ is the highest value, while $Q$ is the length-width ratio of a spore (Bas 1969; Yu et al. 2020).

\section{DNA extraction and sequencing}

DNA was extracted from dried specimens using a NuClean Plant Genomic DNA kit (CWBIO, China). Four DNA regions (ITS, LSU, Tef-1 $a$ and $\beta$-tub) were selected for analysis (Örstadius et al. 2015) and were respectively amplified using the primer pairs ITS1/ITS4 (White et al. 1990), LR0R/LR7 (Hopple and Vilgalys 1999), EF983F/ EF2218R (Örstadius et al. 2015) and B36f/B12r (Nagy et al. 2011). PCR amplifications were performed using the following touchdown programme: $5 \mathrm{~min}$ at $95^{\circ} \mathrm{C}$, followed by 15 rounds of $1 \mathrm{~min}$ at $95^{\circ} \mathrm{C}, 30 \mathrm{~s}$ at $65^{\circ} \mathrm{C}$ (lowered by $1{ }^{\circ} \mathrm{C}$ per cycle) and $1 \mathrm{~min}$ at $72^{\circ} \mathrm{C}$, followed by 20 rounds of $1 \mathrm{~min}$ at $95^{\circ} \mathrm{C}, 30 \mathrm{~s}$ at $50^{\circ} \mathrm{C}$ and $1 \mathrm{~min}$ at $72^{\circ} \mathrm{C}$, with a final extension of $10 \mathrm{~min}$ at $72^{\circ} \mathrm{C}$ (Yan and Bau 2018b). Sequencing was carried out by Qing Ke Biotechnology Co. (Wuhan, China). 
Table I. Sequences used in this study.

\begin{tabular}{|c|c|c|c|c|c|c|}
\hline Taxa & Voucher & Locality & ITS & LSU & $\beta-T u b$ & $t e f-1 \alpha$ \\
\hline Candolleomyces albipes & DED8340 & Sao Tome & KX017209 & - & - & - \\
\hline C. aberdarensis & GLM-F116094 & Kenya & MH880928 & - & - & - \\
\hline C. badhyzensis & 79478 (TAA) Type & Turkmenistan & KC992883 & KC992883 & - & - \\
\hline C. badiophyllus & SZMC-NL-2347 & - & FN430699 & FM876268 & FN396261 & FM897252 \\
\hline \multirow[t]{3}{*}{ C. cacao } & SFSU DED 8339 & Sao Tome & NR148106 & - & - & - \\
\hline & FP1R4 & USA & KU847452 & - & - & - \\
\hline & MP2R2 & USA & KU847436 & - & - & - \\
\hline C. candolleanus & LAS73030 Neotype & Sweden & KM030175 & KM030175 & - & - \\
\hline C. efflorescens & Pegler2133 (K) & Sri Lanka & KC992941 & - & - & - \\
\hline C. eurysporus & GLM-F126263 Type & Germany & MT651560 & MT651560 & - & - \\
\hline C. leucotephrus & LÖ138-01 (UPS) & Sweden & KC992885 & KC992885 & KJ664865 & KJ732775 \\
\hline \multirow[t]{2}{*}{ C. luteopallidus } & Sharp20863 (MICH) Type & USA & KC992884 & KC992884 & - & - \\
\hline & HMJAU5148 & China: Jilin & MG734736 & MW301084 & MW314056 & MW314073 \\
\hline C. secotioides & UES2918 Type & Mexico & KR003281 & KR003282 & - & KR003283 \\
\hline \multirow[t]{2}{*}{ C. singeri } & HMJUA37867 & China: Jilin & MG734718 & MW301088 & MW314059 & MW314077 \\
\hline & HMJAU37877 & China: Chongqing & MW301073 & MW301091 & MW314062 & MW314080 \\
\hline \multirow[t]{5}{*}{ Candolleomyces sp. } & BAB-4773 & India & KP686450 & - & - & - \\
\hline & BAB-5172 & India & KR349656 & - & - & - \\
\hline & BAB- 4748 & India & KR154977 & - & - & - \\
\hline & BAB- 4747 & India & KR154976 & - & - & - \\
\hline & BAB-5202 & India & KT188611 & - & - & - \\
\hline \multirow[t]{5}{*}{ C. subcacao } & HMJAU37807 Type & China: Henan & MW301064 & MW301092 & MW314063 & MW314081 \\
\hline & HMJAU37808 & China: Henan & MW301065 & MW301093 & MW314064 & MW314082 \\
\hline & HFJAU1014 & China: Jiangxi & MW559218 & - & - & - \\
\hline & HFJAU1274 & China: Jiangxi & MW559219 & - & - & - \\
\hline & HFJAU1488 & China:Anhui & MW559220 & - & - & - \\
\hline \multirow[t]{2}{*}{ C. subminutisporus } & HMJAU37801 Type & China: Hubei & MW301066 & MW301094 & MW314065 & MW314083 \\
\hline & HMJAU37916 & China: Henan & MW301067 & MW301095 & MW314066 & MW314084 \\
\hline \multirow[t]{2}{*}{ C. subsingeri } & HMJAU37811 Type & China: Jilin & MG734715 & MW301097 & MW314067 & MW314085 \\
\hline & HMJAU37913 & China: Jilin & MG734725 & MW301098 & MW314068 & MW314086 \\
\hline \multirow[t]{3}{*}{ C. sulcatotuberculosus } & GB:LO55-12 & - & KJ138422 & KJ138422 & - & - \\
\hline & HFJAU1515 & China: Fujian & MW375696 & - & MW382967 & MW382965 \\
\hline & Chiarello 07-10-2013 & - & KJ138423 & - & - & - \\
\hline \multirow[t]{2}{*}{ C. trinitatensis } & TL9035 (C) & Ecuador & КС992882 & KC992882 & KJ664863 & - \\
\hline & ADK4162 (BR) & Togo & KC992886 & KC992886 & - & - \\
\hline Psathyrella cladii-marisci & CLUF302 Type & Italy & MK080112 & & & \\
\hline \multicolumn{7}{|l|}{ Outgroup } \\
\hline Psathyrella multipedata & LÖ237-04 & Sweden & KC992888 & KC992888 & KJ664867 & KJ732777 \\
\hline
\end{tabular}

Note: Newly-generated sequences are in bold.

\section{Data analyses}

Taking into consideration the results of BLAST searching against GenBank and the research of Büttner et al. (2020) and Wächter and Melzer (2020), we analysed ITS, LSU, tef- $1 a\left(\right.$ Tef $1^{\text {st }}$, Tef $2^{\text {nd }}$ and Tef $\left.3^{\text {rd }}\right)$ and $\beta$-tub (Tub $1^{\text {st }}$ and Tub $\left.2^{\text {nd }}\right)$ sequences from 37 taxa. Details are presented in Table 1. Sequences were aligned using the online version of the multiple sequence alignment programme MAFFT v.7 (Katoh and Standley 2013), followed by manual adjustment in BIOEDIT v.7.1.3.0 (Hall 1999). Phylogenetic analyses were conducted using Bayesian Inference (BI) in MrBayes v.3.2.6 (Ronquist et al. 2012) and by Maximum Likelihood (ML) in IQTREE v.1.5.6 (Nguyen et al. 2014). For the BI analyses, four Monte Carlo Markov chains were run 
for 10 million generations, with sampling every $100^{\text {th }}$ generation and with the first $25 \%$ of trees discarded as burn-in (Ronquist et al. 2012). ML analyses were undertaken by applying the ultrafast bootstrap approximation with 1000 replicates. The sequence alignment has been deposited in TreeBASE (S28074).

\section{Results}

According to a BLAST analysis, the ITS sequence of C. subcacao is $98 \%$ similar (eight different loci) to that of C. cacao (Desjardin \& B.A. Perry) D. Wächt. \& A. Melzer and approximately $97 \%$ similar (19 different loci) to five ITS sequences from two unnamed species (KP686450 for BAB-4773, KR349656 for BAB-5172, KR154977 for BAB-4748, KR154976 for BAB-4747 and KT188611 for BAB-5202) isolated from Oeceoclades maculata (Lindley) Lindley (Bayman et al. 2016). The ITS sequence of C. subminutisporus shares $97 \%$ similarity (22 different loci) with that of C. sulcatotuberculosus (J. Favre) D. Wächt. \& A. Melzer. The generated BI and ML trees are shown in Fig. 1 and Suppl. material 1, respectively. In both trees, sequences of the two new species comprise strongly supported clades that are distinct from closely-related taxa. The $C$. subcacao clade groups together with $C$. cacao and two unnamed species with high statistical support, while the C. subminutisporus clade clusters with $C$. singeri (A.H. Sm.) D. Wächt. \& A. Melzer and C. sulcatotuberculosus. The type sequence of Psathyrella cladii-marisci Sicoli, N.G. Passal., De Giuseppe, Palermo \& Pellegrino is clearly nested within Candolleomyces, where it groups most closely, although with only weak to moderate support, with C. badhyzensis (Kalamees) D. Wächt. \& A. Melzer, C. badiophyllus (Romagn.) D. Wächt. \& A. Melzer and C. candolleanus (Fr.) D. Wächt. \& A. Melzer.

\section{Taxonomy}

\section{Candolleomyces subcacao T. Bau \& J.Q. Yan, sp. nov.}

MycoBank No: 839231

Fig. 2

Holotype. China. Henan Province: Bird Island, Nanwan Lake, Xinyang City, $32^{\circ} 06^{\prime} 43.32^{\prime \prime N}, 113^{\circ} 06^{\prime} 03.06 " \mathrm{E}, 124 \mathrm{~m}$ elevation, 17 July 2016, Tolgor Bau, JunQing Yan, HMJAU37807 (holotype!)

Etymology. Referring to its morphological similarity to C. cacao.

Diagnosis. Differs from C. cacao in having a distinct spore germ pore.

Description. Pileus 11-35 mm, spreading hemispherically to planar, hygrophanous, brown (7E7-7E8), striate up to halfway from the margin or indistinct, becoming slightly dirty white (7B1-7B2) upon drying. Veil pale brown (7A5-7B6), thin, fibrillose, falling off easily. Context thin and very fragile, dirty white (7B1-7B2), approximately $1.0 \mathrm{~mm}$ thick at the centre. Lamellae 3.0-4.0 mm wide, moderately 


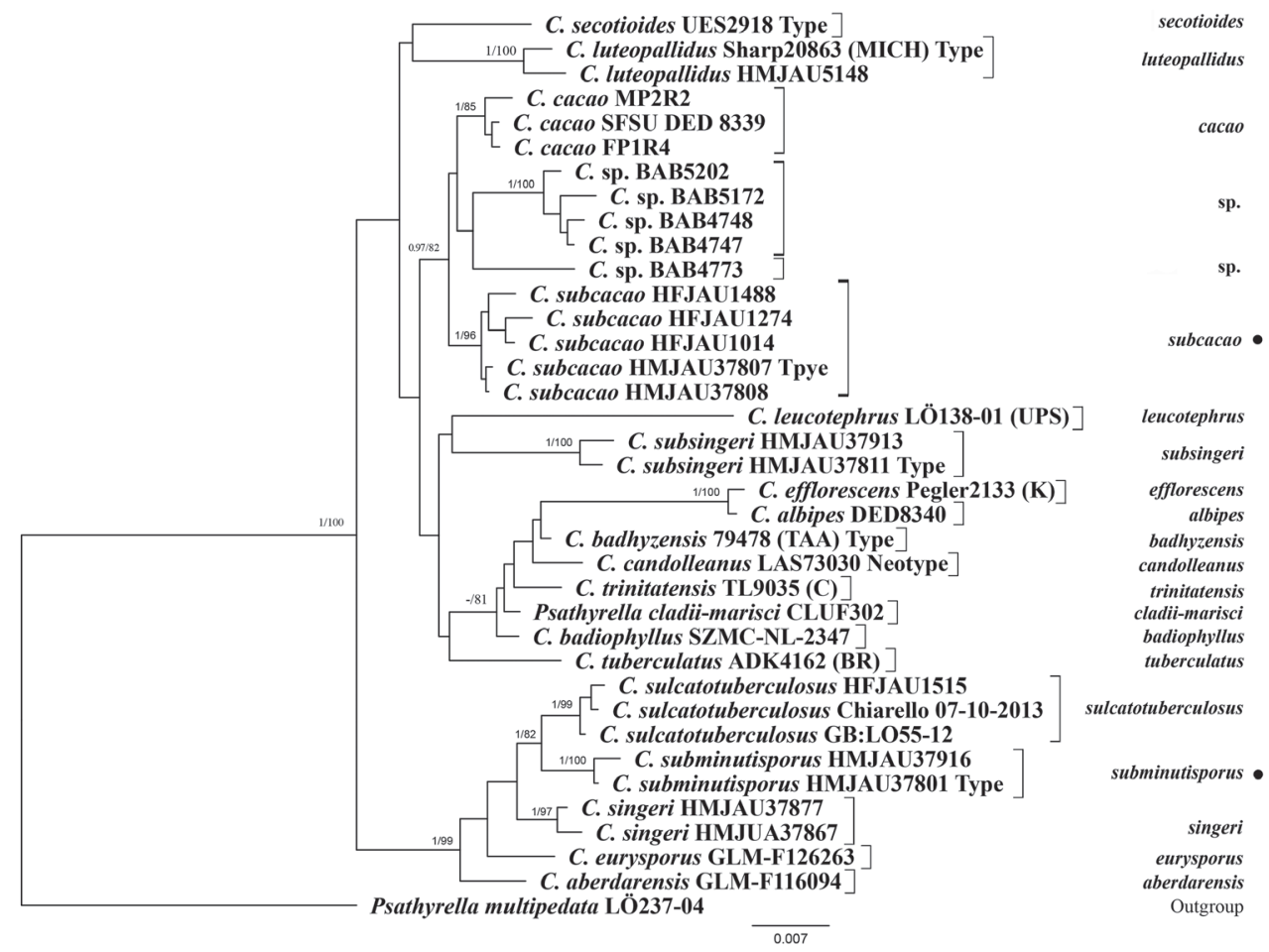

Figure I. Phylogenetic tree of Candolleomyces. The tree was generated by Bayesian analysis of a concatenated dataset of sequences from four nuclear regions (ITS, LSU, tef- $1 a$ and $\beta$-tub). Psathyrella multipedata (Peck) A.H. Sm. was used as an outgroup. Bayesian posterior probabilities (BI-PP) ${ }^{3} 0.95$ and Maximum Likelihood bootstrap support values $(\mathrm{ML}) \geq 75 \%$ are shown above nodes as BI-PP/ML. • indicates newly-described species.

close, adnate to slightly adnexed, pale brown (C3-C4) to dark brown (7D6-7E6), saw-toothed under 20x magnification. Stipe 40-50 mm long, approximately $2.0 \mathrm{~mm}$ thick, white (7A1-7B1), hollow, equal, smooth, with white fibrils (7A1-7B1) at the base. Odour and taste indistinct.

Spores 6.8-8.0(8.8) $\times 3.9-4.9 \mu \mathrm{m}, Q=1.4-1.8$, ellipsoid to oblong-ellipsoid, profile slightly flattened on one side, rarely phaseoliform, inamyloid, smooth, pale yellow-brown, darkening in $5 \% \mathrm{KOH}$, pale brown, germ pores distinct, but small, approximately $1.0 \mu \mathrm{m}$ wide. Basidia $17-22 \times 6.1-7.3 \mu \mathrm{m}$, clavate, hyaline, 4-spored. Pleurocystidia absent. Cheilocystidia 22-36 $\times 9.8-14 \mu \mathrm{m}$, scattered to moderately numerous, various, utriform to fusiform, with an obtuse to broadly obtuse apex, rarely subcapitate or clavate, ovoid, thin-walled. Trama of gills irregular. Pileipellis consisting of 2-3 cells in the deep layer of the subglobose cell, 20-37 $\mu \mathrm{m}$ wide.

Habit and habitat. Solitary to scattered on rotten wood in oak forest.

Other specimens examined. CHinA. Henan Province: Bird Island, Nanwan Lake, Xinyang City, 17 July 2016, Tolgor Bau and Jun-Qing Yan, HMJAU37808, HMJAU37809; Borden Forest Park, Xinyang City, 17 July 2017, Jun-Qing Yan, 

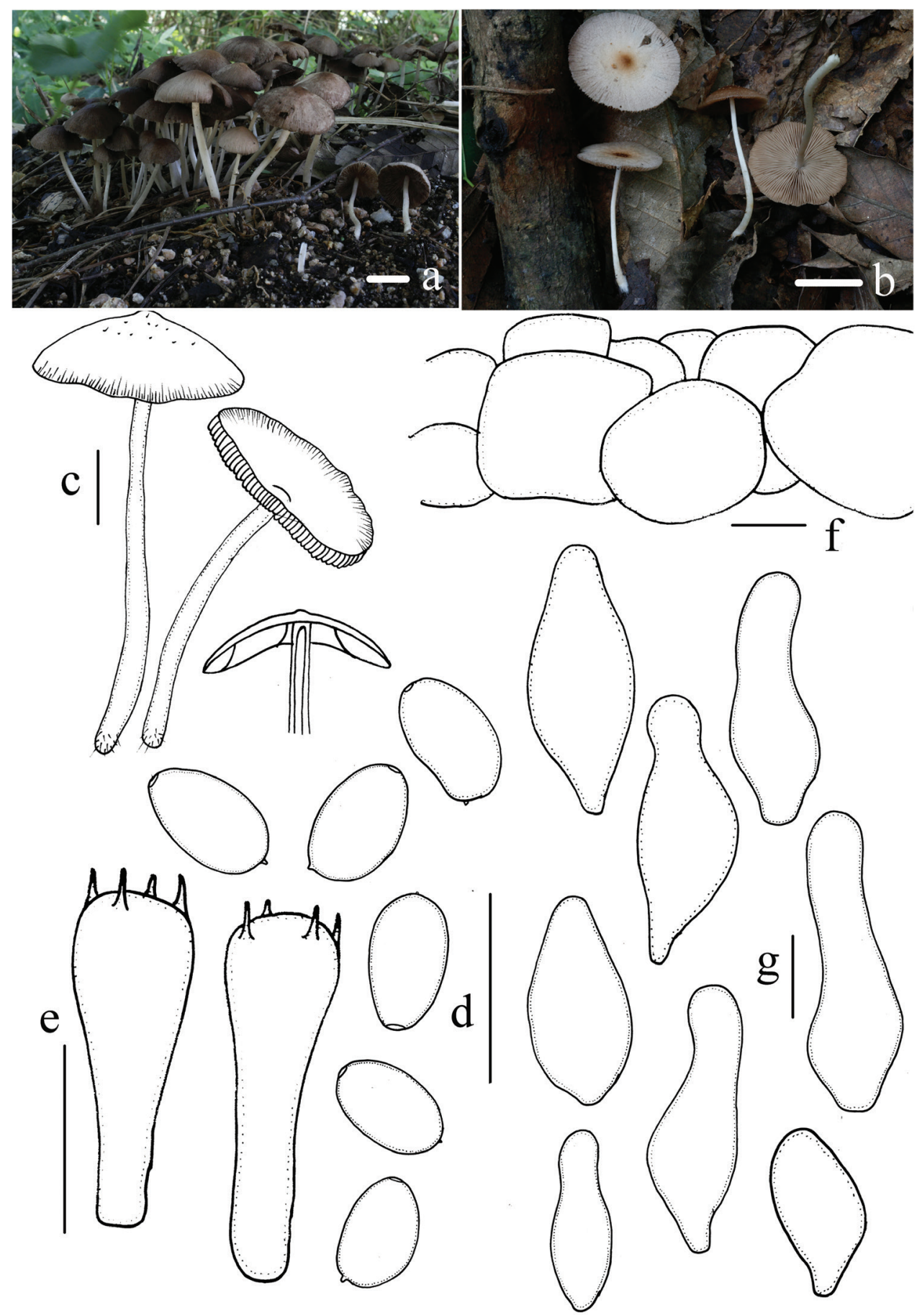

Figure 2. Basidiomata and microscopic features of Candolleomyces subcacao $\mathbf{a}-\mathbf{c}$ Basidiomata $\mathbf{d}$ spores e basidia $\mathbf{f}$ pileipellis $\mathbf{g}$ cheilocystidia. Scale bars: $10 \mathrm{~mm}(\mathbf{a}-\mathbf{c}) ; 10 \mu \mathrm{m}(\mathbf{d}-\mathbf{g})$. 
HMJAU37898, HMJAU37899, HMJAU37900, HMJAU37948, HMJAU44554; Jiangxi Province: Jiangxi Agricultural University, Nanchang City, 3 June 2019, JunQing Yan, HFJAU0716, 9 June 2019, Jun-Qing Yan, HFJAU1274; Yun Bi Feng National Forest Park, Shangrao City, 5 July 2019, HFJAU1014.

\section{Candolleomyces subminutisporus T. Bau \& J.Q. Yan, sp. nov.}

MycoBank No: 839232

Fig. 3

Etymology. Referring to the small spores.

Holotype. China. Henan Province: Boerdeng National Forest Park, Xinyang City, 16 July 2017, Tolgor Bau and Jun-Qing Yan, HMJAU37801 (holotype!).

Diagnosis. Differs from C. sulcatotuberculosus in having smaller spores (5.8$6.8 \mu \mathrm{m}$ long).

Description. Pileus $8.0-22 \mathrm{~mm}$, spreading hemispherically to broadly conical convex, hygrophanous, pale yellow-brown $(6 \mathrm{C} 7-6 \mathrm{C} 8)$ at the centre, pale at the margin (6A2-6A4), striate from margin to centre, becoming pale brown (6B6-6B7) when dry. Veil present in early stages, thin, white (6A1), fibrillose, evanescent. Context thin and very fragile, $1.0-1.5 \mathrm{~mm}$ thick at the centre, same colour as the pileus. Lamellae 2.5$3.0 \mathrm{~mm}$ wide, adnate, moderately close, white (6B1) to pale coffee (6B2-6B3), edges saw-toothed under $20 \times$ magnification. Stipes $15-40 \mathrm{~mm}$ long, $1.0-2.0 \mathrm{~mm}$ thick, cylindrical, hollow, white (6B1), sometimes subhyaline or slightly yellow-brown (6A2$6 \mathrm{~B} 2)$ at the base, apex pruinose, evanescent, slightly expanded at the base. Odour and taste indistinct.

Spores 5.8-6.8(7.8) $\times$ 3.8-4.9 $\mu \mathrm{m}, Q=1.4-1.8$, ovoid, ellipsoid to oblongellipsoid, in profile flattened on one side, rarely phaseoliform, inamyloid, smooth, very pale, nearly hyaline in water and $5 \% \mathrm{KOH}$, germ pore absent. Basidia 14-20 × 7.3-7.8 $\mu \mathrm{m}$, 4-spored, clavate, hyaline. Pleurocystidia absent. Cheilocystidia 20-32 × 11-17 $\mu \mathrm{m}$, utriform, with obtuse apex, bottom side tapering to the long or short stipe. Caulocystidia $27-42 \times 6.1-9.8 \mu \mathrm{m}$, present at the apex, mostly solitary, various, similar to cheilocystidia or clavate and subcapitate or not. Trama of gills irregular. Pileipellis consists of 1-2 cells in a deep layer of the subglobose cell, up to $36 \mu \mathrm{m}$ broad.

Habit and habitat. Scattered on rotten wood or humus in Pinus massoniana and oak forests.

Other specimens examined. China. Anhui Province: Huangshan City, 3 July 2018, Jun-Qing Yan, HFJAU1253, HFJAU1361; Guangxi Zhuang Autonomous Region: Qingxiushan National Forest Park, Nanning City, 12 Aug 2016, HMJAU37930; Phoenix Valley Forest Park, Nanning City, 17 Aug 2016, Jun-Qing Yan, HMJAU37950; Henan Province: Boerdeng National Forest Park, Xinyang City, 16 July 2017, Jun-Qing Yan, HMJAU37916, HMJAU37958; 17 July 2017, Jun-Qing Yan, HMJAU37959, HMJAU37960, HMJAU37961: Hubei Province: Dagui Temple National Forest Park, 

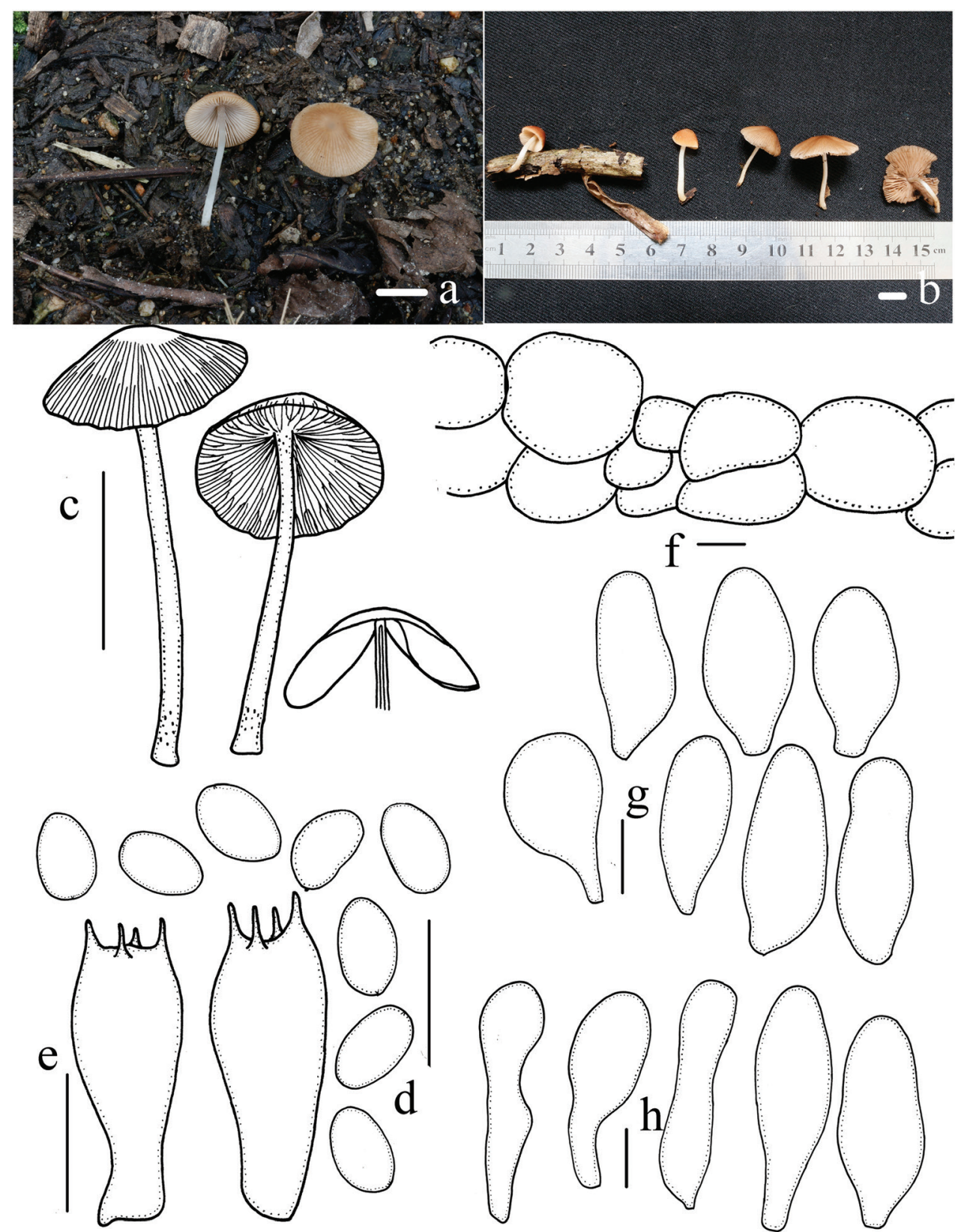

Figure 3. Basidiomata and microscopic features of Candolleomyces subminutisporus a-c Basidiomata $\mathbf{d}$ spores $\mathbf{e}$ basidia $\mathbf{f}$ pileipellis $\mathbf{g}$ cheilocystidia $\mathbf{h}$ caulocystidia. Scale bars: $10 \mathrm{~mm}(\mathbf{a}-\mathbf{c}) ; 10 \mu \mathrm{m}(\mathbf{d}-\mathbf{h})$.

Suizhou City, 16 July 2016, Tolgor Bau and Jun-Qing Yan, HMJAU37800; Jiangxi Province: Lushan Mountain, Jiujiang City, 30 June 2020, Jun-Qing Yan, HFJAU0921; Yunnan Province: Kunming Botanical Garden, Kunming City, 6 Aug 2016, Jun-Qing Yan, HMJAU37929. 


\section{New combination}

Candolleomyces cladii-marisci (G. Sicoli, N.G. Passalacqua, A.B. De Giuseppe, A.M. Palermo \& G. Pellegrino) J.Q. Yan, comb. nov.

MycoBank No: 839233

Psathyrella cladii-marisci Sicoli, N.G. Passal., De Giuseppe, Palermo \& Pellegrino, MycoKeys 52: 99, 2019. Basionym.

Note. According to the ITS phylogenetic analysis including the type specimen, $P$. cladii-marisci belongs to Candolleomyces and has a close phylogenetic relationship with C. candolleanus, C. badiophyllus and C. trinitatensis. In addition, the morphological characteristics of this species correspond to Candolleomyces, which lack pleurocystidia.

For detailed descriptions and line drawings of this species, see Sicoli et al. (2019a; b).

\section{Discussion}

Most species of Candolleomyces have dark brown or brown spores, whereas species with pale spores are rare. Candolleomyces subcacao is very easily confused with $C$. cacao in the field because of their similar macroscopic characteristics. In addition, these two species have highly similar ITS regions (98\%). Nevertheless, some members of Candolleomyces with high ITS similarity are still treated as separate species on the basis of morphological characters (Sicoli et al. 2019a; Büttner et al. 2020; Wächter and Melzer 2020). Candolleomyces subcacao and C. cacao group together, but comprise independent lineages, in the phylogenetic tree (Fig. 1). Moreover, C. cacao has ventricose to broad lageniform cheilocystidia, an indistinct germ pore in 5\% KOH and a tropical distribution (Desjardin 2016).

On the basis of morphology, C. subcacao has been classified into Psathyrella sect. Spintrigerae using the classification system of Kits van Waveren (1985; 1987) and Psathyrella sect. Subatratae, based on the system of Smith (1972). Some species in these sections lack pleurocystidia and may thus actually belong to Candolleomyces, but molecular analyses of type materials are needed prior to their possible reassignment. In this paper, we have, therefore, only compared these species and the new ones with respect to morphology (see the key below). In particular, two species in these sections possess the combined characteristics of small basidiomata, a pale brown and evanescent veil and pale yellow-brown spores with a distinct germ pore: P. lacuum Huijsman, which can be distinguished from $C$. subcacao by the presence of a veil with dispersed white arachnoid fibrils or flocci, abundant pyriform cells at the marginal of the lamellae and very rare utriform cheilocystidia (Kits van Waveren 1985; Battistin et al. 2014) and P. cordobaensis A.H. Sm., which differs mainly in having a $10 \mathrm{~mm}$ wide pileus, an indistinct germ pore and saccate to ellipsoid cheilocystidia (Smith 1972; Desjardin 2016).

Candolleomyces subminutisporus is characterised by the presence of small basidiomata, a pileus that is striate from the margin up to the centre and very pale to nearly hyaline spores that are mainly less than $7.0 \mu \mathrm{m}$ long. Candolleomyces sulcatotuberculo- 
sus and C. subminutisporus are morphologically very similar and are phylogenetically closely related (Fig. 1); however, the former has a sulcate-tuberculose pileus surface and much larger spores, which measure (7.6)7.9-8.5(9) $\times(4.5) 4.6-5.0(5.2) \mu \mathrm{m}($ Einhellinger 1976). Although Kits van Waveren (1985) and Battistini (2014) detected some smaller spores in these species, which measured (6.2)6.9-7.8(8.9) $\times(3.6) 4.1-$ 4.7(5.0) $\mu \mathrm{m}$, most spores of C. sulcatotuberculosus are clearly longer than $7.0 \mu \mathrm{m}$.

Candolleomyces singeri (A.H. Sm.) D. Wächt. \& A. Melzer, C. eurysporus A. Karich, E. Büttner \& R. Ullrich and C. aberdarensis (A. Melzer, Kimani \& R. Ullrich) D. Wächt. $\&$ A. Melzer group together with C. subminutisporus in the phylogenetic tree (Fig. 1). These species can be separated as follows: $C$. singeri has larger spores, mostly 6.8-7.8 $\mu \mathrm{m}$ long (Smith 1972, pers. obs. of HMJUA37867 by JQ Yan), whereas C. eurysporus can be separated on the basis of its broader spores, a $Q$-value of 1.2-1.6(-1.7) and brown lamellae at maturity (Büttner et al. 2020) and C. aberdarensis is distinguished by having larger spores [7.5-8(-8.8) $\mu \mathrm{m}$ long] (Melzer et al. 2018). In addition, two species are morphologically similar to C. subminutisporus in having more-or-less pale spores, germ pores that are indistinct or lacking and no pleurocystidia. These species can be separated from C. subminutisporus as follows: C. halophilus (Esteve-Rav. \& Enderle) D. Wächt. \& A. Melzer has larger spores, which are 8.6-11 × 4.8-6.2 $\mu \mathrm{m}$ (Esteve-Raventós and Enderle 1992; Battistin et al. 2014) and C. subsingeri (T. Bau \& J.Q. Yan) D. Wächt. \& A. Melzer is easily distinguished on the basis of its stout basidiomata (Yan and Bau 2018a).

Finally, P. cladii-marisci was described by Sicoli et. al. (2019) and is characterised by the absence of pleurocystidia and the presence of large spores up to $11 \mu \mathrm{m}$ long (Sicoli et al. 2019a; b). According to our phylogenetic analysis, this species is relatively closely related to C. candolleanus, C. badiophyllus and C. trinitatensis and should be moved to Candolleomyces. A new combination is thus proposed.

\section{Key to related species}

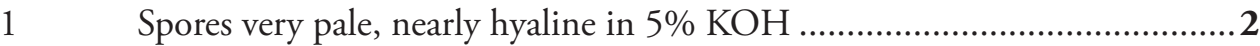

- Spores pale yellow-brown, greyish-brown or darker.....................................

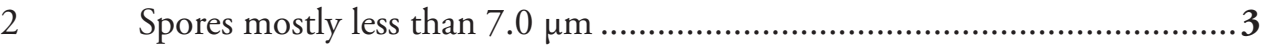

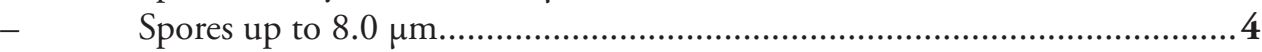

3 Spores broader, $Q=1.2-1.6$, lamellae brown at maturity........ C. eurysporus

- $\quad$ Spores slenderer, $Q=1.4-1.8$, lamellae pale coffee at maturity....

C. subminutisporus

Surface of pileus is sulcate-tuberculose, up to two-thirds of the radius C. sulcatotuberculosus

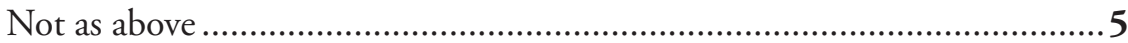

Pileus less than $10 \mathrm{~mm}$ wide, lamellae brown C. aberdarensis

Not as above.

$6 \quad$ Basidiomata stout, spores up to $5.5 \mu \mathrm{m}$ broad.............................. C. singeri

- $\quad$ Basidiomata slender, spores up to $4.5 \mu \mathrm{m}$ broad C. subsingeri Spores up to $11 \mu \mathrm{m}$, growing on plant debris in brackish water.... C. halophilus Not as above...... 
Margin of lamellae with abundant pyriform cells, utriform cheilocystidia very rare....

\section{Acknowledgements}

This work is supported by the National Natural Science Foundation of China (No. 31960008 and 32070010); and Jiangxi Provincial Natural Science Foundation (20202BABL213041). We thank Dr. Barbara Goodson for editing the English text of this manuscript.

\section{References}

Bas C (1969) Morphology and subdivision of Amanita and a monograph of its section Lepidella. Persoonia 5: 96-97.

Battistin E, Chiarello O, Vizzini A, Orstadius L, Larsson E (2014) Morphological characterisation and phylogenetic placement of the very rare species Psathyrella sulcatotuberculosa. Sydowia 66: 171-181.

Bayman P, Mosquera-Espinosa AT, Saladini-Aponte CM, Hurtado-Guevara NC, Viera-Ruiz NL (2016) Age-dependent mycorrhizal specificity in an invasive orchid, Oeceoclades maculata. American Journal of Botany 103: 1880-1889. https://doi.org/10.3732/ajb.1600127

Büttner E, Karich A, Nghi DH, Lange M, Liers C, Kellner H, Hofrichter M, Ullrich R (2020) Candolleomyces eurysporus, a new Psathyrellaceae (Agaricales) species from the tropical Cúc Phương National Park, Vietnam. Austrian Journal of Mycology 28: 79-92. https://doi. org/10.21203/rs.3.rs-57408/v1

Desjardin DE, Perry BA (2016) Dark-spored species of Agaricineae from Republic of São Tomé and Príncipe, West Africa. Mycosphere 7: 359-391. https://doi.org/10.5943/mycosphere/7/3/8

Einhellinger A (1976) Die Pilze in primären und sekundären Pflanzengesellschaften oberbayerischer Moore. Selbst-verlag.

Esteve-Raventós F, Enderle M (1992) Psathyrella halophila spec. nov., eine neue Art aus der Sektion Spintrigerae (Fr.) Konrad \& Maublanc vom Meeresstrand der Insel Mallorca (Spanien). Zeitschrift für Mykologie 58: 205-210.

Fries E (1838) Epicrisis Systematis Mycologici. seu synopsis Hymenomycetum. Uppsala.

Galland MC, Rfo K, Jurand MK (1979) The species problem in the Psathyrella candolleana complex. Mycotaxon 8: 329-332.

Hall TA (1999) BioEdit: a user-friendly biological sequence alignment editor and analysis program for Windows 95/98/NT. Nucleic Acids Symposium Series 41: 95-98. 
Hopple JJ, Vilgalys R (1999) Phylogenetic relationships in the mushroom genus Coprinus and dark-spored allies based on sequence data from the nuclear gene coding for the large ribosomal subunit RNA: divergent domains, outgroups, and monophyly. Molecular Phylogenetics \& Evolution 13: 1-1. https://doi.org/10.1006/mpev.1999.0634

Katoh K, Standley DM (2013) MAFFT multiple sequence alignment software version 7: improvements in performance and usability. Molecular Biology \& Evolution 30: e772. https://doi.org/10.1093/molbev/mst010

Kits van Waveren E (1980) Checklist of synonyms, varieties and forms of Psathyrella candolleana. Transactions of the British Mycological Society 75: 429-437. https://doi.org/10.1016/ S0007-1536(80)80123-9

Kits van Waveren E (1985) The Dutch, French and British species of Psathyrella. Persoonia 2: $1-284$.

Kits van Waveren E (1987) Additions to our monograph on Psathyrella. Thirteen new species, some revised keys, comments on other recently described species, and corrections and additions to our monograph. Persoonia-Molecular Phylogeny and Evolution of Fungi 13: 327-368.

Knudsen H, Vesterholt J (2012) Funga Nordica. Agaricoid, boletoid, cyphelloid and gasteroid genera. Nordsvamp, Copenhagen.

Kornerup A, Wanscher JHK (1978) The Methuen Handbook of Colour ( $3^{\text {rd }}$ ed.). Eyre Methuen Ltd. Reprint., London, 252 pp.

Melzer A, Kimani VW, Ullrich R (2018) Psathyrella aberdarensis, a new species of Psathyrella (Agaricales) from a Kenyan National Park. Austrian Journal of Mycology 27: 23-30.

Nagy LG, Walther G, Házi J, Vágvölgyi C, Papp T (2011) Understanding the Evolutionary Processes of Fungal Fruiting Bodies: Correlated Evolution and Divergence Times in the Psathyrellaceae. Systematic Biology 60: 303-317. https://doi.org/10.1093/sysbio/syr005

Nguyen LT, Schmidt HA, von Haeseler A, Minh BQ (2014) IQ-TREE: a fast and effective stochastic algorithm for estimating maximum-likelihood phylogenies. Molecular Biology and Evolution 32: 268-274. https://doi.org/10.1093/molbev/msu300

Örstadius L, Kundsen H (2012) Psathyrella (Fr.) Quél. In: Knudsen H, Vesterholt J (Eds) Funga Nordica Agaricoid, boletoid, cyphelloid and gasteroid genera. Nordsvamp, Copenhagen, 586-623.

Örstadius L, Ryberg M, Larsson E (2015) Molecular phylogenetics and taxonomy in Psathyrellaceae (Agaricales) with focus on psathyrelloid species: introduction of three new genera and 18 new species. Mycological Progress 14: 1-42. https://doi.org/10.1007/s11557-015-1047-x

Ronquist F, Teslenko M, Van Der Mark P, Ayres DL, Darling A, Höhna S, Larget B, Liu L, Suchard MA, Huelsenbeck JP (2012) MrBayes 3.2: efficient Bayesian phylogenetic inference and model choice across a large model space. Systematic Biology 61: 539-542. https://doi.org/10.1093/sysbio/sys029

Sicoli G, Passalacqua NG, De Giuseppe AB, Palermo AM, Pellegrino G (2019a) A new species of Psathyrella (Psathyrellaceae, Agaricales) from Italy. MycoKeys 52: 89-102. https://doi. org/10.3897/mycokeys.52.31415

Sicoli G, Passalacqua NG, De Giuseppe AB, Palermo AM, Pellegrino G (2019b) Corrigendum: Sicoli G, Passalacqua NG, De Giuseppe AB, Palermo AM, Pellegrino G (2019) A new species of Psathyrella (Psathyrellaceae, Agaricales) from Italy. MycoKeys 52: 89-102. MycoKeys 58: e129. https://doi.org/10.3897/mycokeys.58.38856 
Smith AH (1972) The North American species of Psathyrella. The New York Botanical Garden 24: 1-633.

Wächter D, Melzer A (2020) Proposal for a subdivision of the family Psathyrellaceae based on a taxon-rich phylogenetic analysis with iterative multigene guide tree. Mycological Progress 19: 1151-1265. https://doi.org/10.1007/s11557-020-01606-3

White TJ, Bruns TD, Lee SB, Taylor JW, Innis MA, Gelfand DH, Sninsky JJ (1990) Amplification and direct sequencing of Fungal Ribosomal RNA Genes for phylogenetics. Academic Press, San Diego, 315-322. https://doi.org/10.1016/B978-0-12-372180-8.50042-1

Yan JQ (2018) Taxonomy and Molecular Phylogeny of Psathyrella and related genera in China, Jiangxi Agricultural University.

Yan JQ, Bau T (2018a) The Northeast Chinese species of Psathyrella (Agaricales, Psathyrellaceae). MycoKeys 33: 1-85. https://doi.org/10.3897/mycokeys.33.24704

Yan JQ, Bau T (2018b) Psathyrella alpina sp. nov. (Psathyrellaceae, Agaricales), a new species from China. Phytotaxa 349: 85-91. https://doi.org/10.11646/phytotaxa.349.1.11

Yu WJ, Chang C, Qin LW, Zeng NK, Wang SX, Fan YG (2020) Pseudosperma citrinostipes (Inocybaceae), a new species associated with Keteleeria from southwestern China. Phytotaxa 450: 8-16. https://doi.org/10.11646/phytotaxa.450.1.2

\section{Supplementary material I}

\section{Phylogram generated by Maximum Likelihood (ML) analysis}

Authors: Tolgor Bau, Jun-Qing Yan

Data type: phylogenetic tree

Explanation note: Phylogram generated by Maximum Likelihood (ML) analysis of Candolleomyces based on sequences of a concatenated data set from four nuclear regions (ITS, LSU, Tef-1a and $\beta$-tub), rooted with Psathyrella multipedata (Peck) A.H. Sm. (/multipedata clade). ML bootstrap proportion (ML-BP) $\geq 75 \%$ are shown. - indicates newly described species.

Copyright notice: This dataset is made available under the Open Database License (http://opendatacommons.org/licenses/odbl/1.0/). The Open Database License $(\mathrm{ODbL})$ is a license agreement intended to allow users to freely share, modify, and use this Dataset while maintaining this same freedom for others, provided that the original source and author(s) are credited.

Link: https://doi.org/10.3897/mycokeys.80.67166.suppl1 